\title{
Induced sputum cell profiles in lung transplant recipients with or without chronic rejection: correlation with lung function
}

\author{
K M Beeh, O Kornmann, J Lill, R Buhl
}

\begin{abstract}
Background-Sputum induction is a noninvasive procedure for measuring inflammatory processes of the lower respiratory tract. The aim of this study was to establish sputum cell counts and differentials in patients after lung transplantation (LTx), with or without chronic transplant rejection.

Methods-Sputum induction was performed in $41 \mathrm{LTx}$ patients (25 single LTx (sLTx), 16 double LTx (dLTx) and 15 healthy non-smoking volunteers. Sputum was processed according to standard protocols. Total cell count was calculated as mean (SE) cells $\times 10^{6} / \mathrm{ml}$ sputum and cell differential (\%) was evaluated after staining. Cellular profiles were correlated with lung function.

Results-Total sputum cell counts were increased in sLTx $\left(9(1.9)\right.$ cells $\times 10^{6} / \mathrm{ml}$, $p=0.01)$ and dLTx patients $\left(7.2(1.5) \times 10^{6} /\right.$ $\mathrm{ml}, \mathrm{p}=0.01)$ compared with healthy controls $\left(2.6(0.6) \times 10^{6} / \mathrm{ml}\right)$. There was also a marked sputum neutrophilia in both patient groups $(59(6) \%$ and $62(6) \%$, respectively, $\mathrm{p}<0.001 v$ controls). Moreover, in both sLTx and dLTx patients with chronic transplant rejection there was an increased number of sputum neutrophils compared with patients with normal graft function ( $p<0.05$ both comparisons), and neutrophils were inversely correlated with lung function (forced expiratory volume in one second $\left(F E V_{1}\right) \%$ predicted): sLTx, $r=-0.61, \mathrm{p}=0.001 ; \mathrm{dLT} x, r=-0.75, \mathrm{p}=0.001$, respectively). Sputum lymphocytes and eosinophils were similar in both groups. No relevant side effects occurred during sputum induction.
\end{abstract}

Conclusions-Sputum induction is a safe and non-invasive tool for monitoring lower respiratory tract inflammation in LTx patients. Both sLTx and dLTx patients with chronic rejection had increased sputum neutrophils compared with patients with normal transplant function. These data support findings of other authors highlighting a possible role for neutrophils in the pathogenesis of chronic transplant rejection.

(Thorax 2001;56:557-560)

Keywords: lung transplantation; sputum; rejection

Lung transplantation (LTx) has become a therapeutic option for a growing number of patients with end stage lung disease-for example, idiopathic pulmonary fibrosis (IPF), cystic fibrosis (CF), chronic obstructive pulmonary disease (COPD), or pulmonary hypertension. ${ }^{1}$ However, despite recent improvements in surgical procedures and posttransplant immunosuppression, overall prognosis after lung transplantation is limited with a 2 year survival rate of $70-80 \%$ and a 5 year survival of only $50-60 \% .^{2-4}$ Besides pulmonary infection, chronic transplant failure due to rejection is the major cause of transplant associated morbidity and mortality. ${ }^{5}$ Chronic transplant rejection is characterised by a progressive decline in pulmonary function associated with inflammatory processes leading to tissue damage and fibrosis, predominantly in the small airways. ${ }^{7}$ Chronic rejection is often referred to as "bronchiolitis obliterans syndrome" (BOS), although knowledge of the pathogenesis of BOS is limited. Most evidence suggests a combined role of host immune responses to the allograft and pulmonary infection, especially cytomegalovirus (CMV) infection, as major trigger factors for BOS. ${ }^{7}$

Transbronchial biopsy is the gold standard for detecting histological changes in allografts consistent with BOS. ${ }^{8}$ However, transbronchial biopsies carry some potential risks such as alveolar bleeding or pneumothorax. Other diagnostic tools such as high resolution computed tomography (HRCT) or spirometry are therefore used to monitor transplant function, and diagnosis of BOS is based on clinical criteria as proposed by the International Society of Heart and Lung Transplantation. ${ }^{8}$ Despite this, there is an emerging need for non-invasive procedures to evaluate lower respiratory tract inflammation in LTx patients.

Sputum induction has been extensively used to characterise inflammatory processes in patients with asthma or COPD. ${ }^{9}{ }^{10}$ It provides a reliable and safe non-invasive tool for studying cellular and soluble components of the lower respiratory tract which may be applied to a variety of pulmonary disorders. Until now the potential value of sputum induction in patients with LTx has not been assessed. Thus, the aim of this cross sectional study was to evaluate sputum cell counts and differentials in LTx patients, and to determine whether chronic rejection is accompanied by an alteration in the pattern of the cellular components in the respiratory tract which may also be correlated with lung function in these patients. 
Table 1 Mean (SE) sputum cell counts of healthy controls and patients undergoing lung transplantation

\begin{tabular}{llll}
\hline & $\begin{array}{l}\text { Controls } \\
(n=15)\end{array}$ & $\begin{array}{l}s L T x \\
\text { patients } \\
(n=25)\end{array}$ & $\begin{array}{l}\text { dLTx } \\
\text { patients } \\
(n=16)\end{array}$ \\
\hline $\begin{array}{l}\text { Total cell count } \\
\quad\left(\times 10^{6} / \mathrm{ml} \mathrm{sputum}\right)\end{array}$ & $2.6(0.6)^{\star}$ & $9(1.9)$ & $7.2(1.5)$ \\
$\begin{array}{l}\text { Macrophages (\%) } \\
\text { Neutrophils (\%) }\end{array}$ & $79(3)^{\star \star}$ & $36(5)$ & $34(7)$ \\
$\begin{array}{l}\text { Lymphocytes (\%) } \\
\text { Eosinophils (\%) }\end{array}$ & $3.6(0.6)$ & $59(6)$ & $62(6)$ \\
\hline
\end{tabular}

SLTx = single lung transplantation; dLTx $=$ double lung transplantation.

${ }^{\star} \mathrm{p}<0.05 v$ sLTx and dLTx patients, respectively; ${ }^{\star \star} \mathrm{p}<0.001 v$ sLTx and dLTx patients, respectively.

\section{Methods}

PATIENTS

The study population consisted of 41 LTx patients $(76 \%$ men) of mean age 49 years (range 18-64 years. The underlying diseases were pulmonary emphysema $(n=19)$, IPF $(n=13)$, cystic fibrosis $(n=6)$, and others $(n=3)$. Twenty five patients had undergone single lung transplantation (sLTx) and 15 patients had undergone double lung transplantation (dLTx). One patient with cystic fibrosis had received a single re-transplant after initial dLTx. Immunosuppressive regimens following transplantation were either a combination of azathioprine/cyclosporin A (CsA, n=24), mycophenolate/CsA $(n=10)$, or mycophenolate/tacrolimus ( $\mathrm{FK} 506, \mathrm{n}=7$ ), together with low dose corticosteroids (10-20 mg/day).

Fifteen healthy, non-smoking adults $(60 \%$ men) of mean age 30 years (range 20-38) without a history of atopy or respiratory disorders served as controls. The study was approved by the local ethics committee and all patients were informed of the purpose of the study and gave informed written consent.

CLINICAL EVALUATION AND EXCLUSION OF ACTIVE INFECTION

Patients with LTx were clinically evaluated on presentation to the outpatient transplant clinic or during hospital stays for routine procedures. Standard procedures included chest radiography and spirometric tests (Jaeger, Masterlab II, Wuerzburg, Germany). Spirometric measurements included forced expiratory volume in one second $\left(\mathrm{FEV}_{1}\right)$ and forced vital capacity (FVC) manoeuvres.

To minimise the possibility of airway infection, only patients without clinical signs of active infection such as fever or malaise were included. Furthermore, chest radiographs, leucocyte count, and serum $\mathrm{C}$ reactive protein (CRP) levels had to be normal or unchanged. Sputum samples were also cultured to detect microbiological organisms and the results had to be negative or considered as low grade colonisation only if positive.

A diagnosis of chronic rejection was either based on histological findings in the bronchial biopsy specimens or clinical criteria of a progressive decline in lung function or gas exchange over time, a consistent chest radiograph or HRCT scan, or a combination of these, as proposed by the consensus report of the International Society of Heart and Lung Transplantation. ${ }^{8}$
SPUTUM INDUCTION

Sputum induction was performed according to a method previously described ${ }^{9}$ with slight modifications. Patients inhaled $4 \%$ hypertonic saline delivered by an ultrasonic nebuliser device (UltraNeb 2000, DeVilbiss, UK) for 15 minutes. They were then told to rinse their mouth, blow their nose, and carefully cough sputum into a petri dish using forced expiratory manoeuvres. If the induction was well tolerated, the first portion of sputum was discarded and the inhalation procedure was repeated for another 15 minutes. Lung function was carefully monitored by spirometric tests every 5 minutes during induction to ascertain safety of the procedure. Induction was stopped when a fall in $\mathrm{FEV}_{1}$ of $>20 \%$ occurred and patients were given two puffs of salbutamol (100 $\mu \mathrm{g} /$ puff).

\section{SPUTUM PROCESSING AND COUNTING}

Sputum plugs were carefully separated from salivary secretions and examined by light microscopy to ascertain the least possible contamination of sputum with saliva and squamous cells. An appropriate sample was then filled into a $1 \mathrm{ml}$ Eppendorf cup, weighed, and mixed with twice the volume of dithiotreitol (DTT 0.1\%, Calbiochem, Germany). The sputum was gently vortexed and placed into a water bath at $37^{\circ} \mathrm{C}$ for 15 minutes to allow homogenisation of the sample, with repeated mixing. Phosphate buffered saline (PBS, Gibco Life, UK) was added to achieve a 20 -fold dilution and the samples were centrifuged at $400 \mathrm{~g}$ for 10 minutes. The supernatant was discarded and the cell pellet was resuspended in 200$400 \mu \mathrm{l}$ PBS with $1 \%$ bovine serum albumin (BSA, Sigma Chemicals, Germany). $20 \mu \mathrm{l}$ of cell suspension was added to $5 \mu$ trypan blue, vortexed, and $10 \mu \mathrm{l}$ of the solution was then counted in a Neubauer cell chamber. Viable cells were counted and the total cell count was calculated as cell count $/ \mathrm{ml}$ sputum. For cytospins, an adequate sample of the cell suspension was added to a cytospin tube to achieve a total number of $20000-30000$ cells per slide, spun for 5 minutes, fixed and stained with Hemacolor staining (Merck, Germany) to allow differentiation of squamous cells, macrophages, neutrophils, eosinophils, and lymphocytes. Cytospin quality was regarded adequate when contamination with squamous cells was less than $20 \%$. A total of 400 non-squamous cells were then independently counted by two blinded observers. The relative proportion of cell types was counted as the percentage of all non-squamous cells.

\section{STATISTICAL ANALYSIS}

Statistical analysis was performed using the STATA 5.0 intercooled software package (Stata Corp, Texas, USA) for personal computer. Unless otherwise stated, data are given as mean (SE) values or median for time after transplantation. The Kolmogorov-Smirnov test was used to test variables for normal distribution. Differences between groups were measured using the Mann-Whitney $U$ test for nonnormally distributed values and the Student's $t$ 
Table 2 Mean (SE) sputum cell counts of lung transplantation patients with or without chronic rejection

\begin{tabular}{|c|c|c|c|c|}
\hline & \multicolumn{2}{|c|}{$s L T x$ patients $(n=25)$} & \multicolumn{2}{|c|}{$d L T x$ patients $(n=16)$} \\
\hline & $\begin{array}{l}\text { Rejection - } \\
(n=13)\end{array}$ & $\begin{array}{l}\text { Rejection }+ \\
(n=12)\end{array}$ & $\begin{array}{l}\text { Rejection - } \\
(n=7)\end{array}$ & $\begin{array}{l}\text { Rejection }+ \\
(n=9)\end{array}$ \\
\hline $\mathrm{FEV}_{1}(\mathrm{l})$ & $2.31(0.13)^{\star}$ & $1.44(0.1)$ & $2.6(0.25)^{\star}$ & $1.48(0.12)$ \\
\hline $\mathrm{FEV}_{1}(\%$ predicted $)$ & $66(4)^{\star}$ & $45(3)$ & $75(7)^{\star}$ & $38(3)$ \\
\hline $\mathrm{FEV}_{1} \% \mathrm{FVC}$ & $77(5)^{\star}$ & $60(7)$ & $93(4)^{\star}$ & $57(5)$ \\
\hline $\mathrm{CRP}$ & $27(20)$ & $24(14)$ & $5(2)$ & $18(9)$ \\
\hline $\begin{array}{l}\text { Total cell count } \\
\left(\times 10^{6} / \mathrm{ml}\right. \\
\text { sputum })\end{array}$ & $3.7(0.6)^{\star \star}$ & $14.9(3.2)$ & $5(1.4)$ & $9(2.3)$ \\
\hline Macrophages (\%) & $48(8)^{\star \star \star}$ & $22(5)$ & $54(12)^{\star \star \star}$ & $19(4)$ \\
\hline Neutrophils (\%) & $48(9)^{\star \star \star}$ & $72(5)$ & $43(10)^{\star \star \star}$ & $77(4)$ \\
\hline Lymphocytes (\%) & $2.6(0.9)$ & $3.6(0.7)$ & $2.4(0.6)$ & $2.7(0.8)$ \\
\hline Eosinophils (\%) & $0.9(0.4)$ & $0.4(0.2)$ & $0.5(0.3)$ & $1.7(1.1)$ \\
\hline
\end{tabular}

$\mathrm{FEV}_{1}=$ forced expiratory volume in one second $\mathrm{FVC}=$ forced vital capacity $\mathrm{CRP}=\mathrm{C}$ reactive protein

${ }^{\star} \mathrm{p}<0.001 ;{ }^{\star \star} \mathrm{p}<0.01 ;{ }^{\star \star \star} \mathrm{p}<0.05$.

test for normally distributed values. Unless otherwise stated, patients undergoing sLTx and dLTx were analysed separately. Correlational analysis was performed by simple linear regression. Since the total sputum cell counts were $\log$ normally distributed, log values were used for correlational analysis. A p value of less than 0.05 was considered statistically significant.

\section{Results}

Twenty one patients undergoing lung transplantation met the clinical criteria of chronic transplant rejection while the other 20 had apparently normal graft function (12/25 sLTx, 9/16 dLTx). The time elapsed after transplantation was higher in patients with chronic rejection than in those without (median $732 v$ 241 days after transplantation, $\mathrm{p}=0.02)$. Sputum cultures were positive for Pseudomonas cepacia in two patients with underlying cystic fibrosis and for Staphylococcus aureus in another two patients with pulmonary emphysema. One patient who underwent sLTx for $\alpha_{1}$-antitrypsin deficiency was sputum positive for Aspergillus fumigatus.

Serum CRP levels were similar in both sLTx and dLTx patients with or without chronic rejection. Absolute and relative values of $\mathrm{FEV}_{1}$ and the ratio of $\mathrm{FEV}_{1} / \mathrm{FVC}$ were significantly lower in patients with chronic rejection.

SAFETY

Sputum induction was safe and well tolerated by all patients. No significant fall in $\mathrm{FEV}_{1}$ (>20\% change from baseline) was observed in any patient. The mean change in $\mathrm{FEV}_{1}$ after induction was -37 (41) ml. Single minor complaints were not clinically significant and included sensory dysfunction $(n=1)$ and dry cough $(n=1)$, both of which were temporary and reversed spontaneously within a few hours after the procedure. During a 4 week follow up period none of the patients developed respiratory tract infection.

\section{SPUTUM CELLS}

Compared with healthy controls, LTx patients in general had significantly higher total cell counts and percentage of neutrophils while the

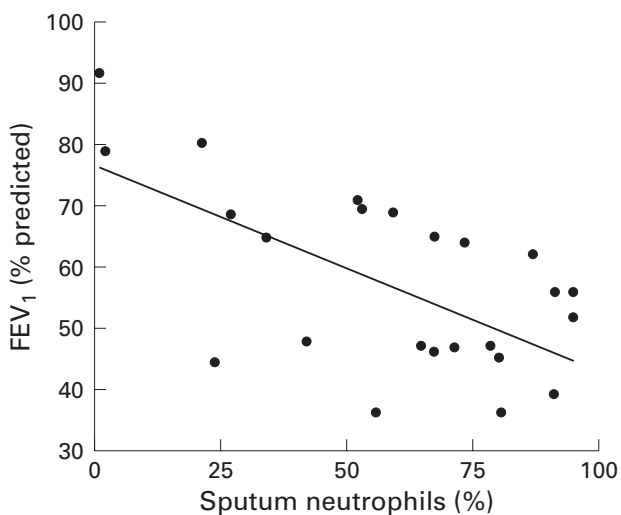

Figure 1 Correlation of sputum neutrophils and lung function ( $F E V_{1} \%$ predicted) in 25 patients undergoing single lung transplantation $(r=-0.61 ; p=0.001)$.

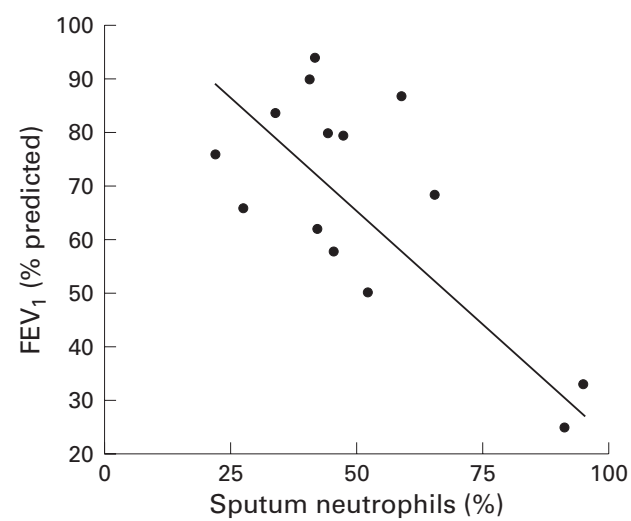

Figure 2 Correlation of sputum neutrophils and lung function (FEV,\% predicted) in 16 patients undergoing double lung transplantation $(r=-0.75 ; p=0.001)$.

relative proportion of macrophages was reduced. No differences were observed between sputum lymphocyte or eosinophil counts (table $1)$.

In both sLTx and dLTx patients, those with established chronic rejection had higher sputum neutrophil counts than patients with normal transplant function. Total cell counts were also increased in patients with chronic rejection, although this observation only reached statistical significance in sLTx patients. No differences were seen in the lymphocyte and eosinophil differential counts in any of the subgroups (table 2).

Log total sputum cell counts and the proportion of sputum neutrophils were also inversely correlated with $\%$ predicted $\mathrm{FEV}_{1}$ values. This observation was true for both sLTx (log total cells: $r=-0.35, p=0.07$, fig 1) and dLTx patients (log total cells: $r=-0.5$, $\mathrm{p}=0.04$, fig 2).

\section{Discussion}

Chronic transplant rejection is the major cause limiting the overall prognosis of patients after lung transplantation. Since standard techniques to monitor rejection are often invasive and may therefore bear a significant risk for the patients, there is a need for non-invasive procedures to monitor lower respiratory tract inflammation in LTx patients. This study was performed to evaluate the role of sputum induction in lung transplantation. 
Sputum induction was safe and well tolerated by all LTx patients and healthy volunteers. No significant fall in $\mathrm{FEV}_{1}$ was observed in any patient, and minor complaints were negligible. Despite this, because of the underlying immunosuppression in these highly susceptible individuals, hygiene precautions should be undertaken to avoid contamination of the nebuliser, valves, or tubes, and sterile disposable equipment should be used.

Since patients have different lung diseases after sLTx and dLTx, with the native lung remaining in situ in sLTx patients, these two groups were analysed separately. Compared with healthy volunteers, both groups of patients had significantly increased total sputum cell counts and a higher proportion of sputum neutrophils. This observation was independent of established chronic rejection. The general increase in cell count and neutrophils may be due, at least in part, to treatment with oral corticosteroids which have the potential to increase blood and tissue neutrophils. ${ }^{11}$ However, total cells and neutrophils in both transplantation groups were increased even more in those patients with chronic rejection, despite the fact that there was no difference in corticosteroid therapy between these groups. Moreover, a significant correlation of total sputum cell counts and sputum neutrophils with the severity of airflow obstruction was observed in both groups of patients.

With regard to sputum neutrophilia, lower respiratory tract infection was assumed to be a major confounding factor affecting the interpretation of the observed cellular profiles in the population under survey. We have therefore carefully evaluated the patients to minimise the possibility of underlying infection. Only patients with no clinical abnormalities, leucocytosis, and increased serum CRP levels were studied. Apart from the five patients discussed earlier, sputum cultures revealed no bacterial or fungal growth in any sample and the organisms grown were considered to represent colonisation rather than infection. Moreover, these patients did not have the lowest $\mathrm{FEV}_{1}$ values, hence inclusion in the analysis did not bias the basic results of our study.

In contrast to bronchoalveolar lavage samples, the assessment of induced sputum cells in single lung transplant recipients is problematic because it cannot be ascertained clearly whether the sputum sample derives from the transplanted allograft or the residual lung. It is therefore possible that the underlying pathology in the native lung contributes to the sputum neutrophilia, especially since the sLTx patients in this cross sectional analysis predominantly had IPF or COPD, both of which are associated with accumulation of neutrophils in the lower respiratory tract. ${ }^{12}{ }^{13}$ Nevertheless, even in these patients we found a clear negative correlation between sputum neutrophilia and severity of airflow limitation.

It therefore appears likely that sputum neutrophilia reflects an underlying inflammatory process involved in the pathogenesis of chronic rejection, promoting inflammation, tissue damage, and airway wall remodelling. These findings are in agreement with bronchoalveolar lavage and biopsy studies which have consistently reported a marked neutrophilia in lavage fluid ${ }^{14-17}$ or lung tissue ${ }^{18} 19$ during chronic rejection.

We conclude that sputum induction provides a safe non-invasive tool for measuring airway inflammation in LTx patients. Further studies will evaluate the sensitivity of serial sputum induction and the predictive value for chronic rejection in LTx patients. Further elucidation of the possible contribution of neutrophils to chronic rejection is also necessary, since novel anti-inflammatory drugs targeting neutrophils, such as leukotriene $\mathrm{B}_{4}$ antagonists ${ }^{20}$ or selective phosphodiesterase inhibitors, ${ }^{21}$ may offer potential therapeutic benefit in this condition.

1 Benfield JR, Wain JC. The history of lung transplantation. Chest Surg Clin North Am 2000;10:189-99.

2 Hosenpud JD, Bennett LE, Keck BM, et al. Effect of diagnosis on survival benefit of lung transplantation for end-stage lung disease. Lancet 1998;351:24-7.

3 Harringer W, Wiebe K, Struber M, et al. Lung transplantation: 10-year experience. Eur $\mathcal{f}$ Cardiothorac Surg 1999;16:546-54.

4 Meyers BF, Lynch J, Trulock EP, et al. Lung transplantation: a decade of experience. Ann Surg 1999; 230:362-70.

5 Paradis I. Bronchiolitis obliterans: pathogenesis, prevention, and management. Am $\mathcal{F}$ Med Sci 1998;315:161-78.

6 Heng D, Sharples LD, McNeil K, et al. Bronchiolitis obliterans syndrome: incidence, natural history, prognosis,

7 Boehler A, Estenne M. Obliterative bronchiolitis after lung transplantation. Curr Opin Pulmon Med 2000;6:133-9.

8 Cooper JD, Billingham M, Egan T, et al. A working formuation for the standardization of nomenclature for clinical staging of chronic dysfunction in lung allografts. International Society for Heart and Lung Transplantation. 7 Heart Lung Transplant 1993;12:713-6.

9 Pizzichini E, Pizzichini MMM, Efthimiadis A, et al. Indices of airway inflammation in induced sputum: reproducibility and validity of cell and fluid-phase measurements. $A m \mathcal{F}$ Respir Crit Care Med 1996;154:308-17.

10 Ronchi MC, Piragino C, Rosi E, et al. Role of sputum differential cell count in detecting airway inflammation in patients with chronic bronchial asthma or COPD. Thorax 1996;51:1000-4.

11 Crockard AD, Boylan MT, Droogan AG, et al. Methylprednisolone-induced neutrophil leukocytosis: down-modulation of neutrophil L-selectin and Mac-1 expression and induction of granulocyte-colony stimulating factor. Int 7 Clin Lab Res 1998;28:110-5.

12 Chan-Yeung M, Mueller NL. Cryptogenic fibrosing alveolitis. Lancet 1997;350:651-6.

13 Bhowmik A, Seemungal TAR, Sapsford RJ, et al. Relation of sputum inflammatory markers to symptoms and lung function changes in COPD exacerbations. Thorax 2000;55: 114-20.

14 Tiroke AH, Bewig B, Haverich A. Bronchoalveolar lavage after lung transplantation. State of the art. Clin Transplant 1999;13:131-57.

15 Henke JA, Golden JA, Yelin EH, et al. Persistent increases of BAL neutrophils as a predictor of mortality following lung transplant. Chest 1999;115:403-9.

16 Zheng L, Walters EH, Ward C, et al. Airway neutrophilia in stable and bronchiolitis obliterans syndrome patients following lung transplantation. Thorax 2000;55:53-9.

17 DiGiovine B, Lynch JP, Martinez FJ, et al. Bronchoalveolar lavage neutrophilia is associated with obliterative bronchiolitis after lung transplantation: role of IL-8. F Immunol 1996;157:4194-202.

18 Riise GC, Williams A, Kjellstrom C, et al. Bronchiolitis obliterans syndrome in lung transplant recipients is associated with increased neutrophil activity and decreased antioxidant status in the lung. Eur Respir f 1998;12:82-8.

19 McDonald JW, Keller CA, Ramos RR, et al. Mixed (neutrophil-rich) interstitial pneumonitis in biopsy specimen of lung allografts: a clinicopathologic evaluation. Chest 1998;113:117-23.

20 Lee E, Lindo T, Jackson N, et al. Reversal of human neutrophil survival by leukotriene $\mathrm{B}(4)$ receptor blockade and 5 -lipoxygenase and 5-lipoxygenase activating protein inhibitors. Am f Respir Crit Care Med 1999;160:2079-85.

21 Nielson CP, Vestal RE, Sturm RJ, et al. Effect of selective phosphodiesterase inhibitors on the polymorphonuclear phosphodiesterase inhibitors on the polymorphonuclear 1990;86:801-8. 